\title{
Vitrification of ICSI- and IVF-derived bovine blastocysts by minimum volume cooling procedure: effect of developmental stage and age
}

\author{
H. Abdalla ${ }^{\text {a,b }}$, M. Shimoda ${ }^{\text {a }}$, H. Hara ${ }^{\text {a }}$, H. Morita $^{c}$, M. Kuwayama ${ }^{c}$, M. Hirabayashi ${ }^{\text {dee }}$, \\ S. Hochi ${ }^{\text {a,f, } *}$
}

${ }^{a}$ Graduate School of Science and Technology, Shinshu University, Ueda, Nagano 386-8567, Japan

${ }^{b}$ Faculty of Veterinary Medicine, Zagazig University, Zagazig, Sharkia 44519, Egypt

${ }^{c}$ Kato Ladies Clinic, Shinjuku, Tokyo 160-0023, Japan

${ }^{d}$ National Institute for Physiological Sciences, Okazaki, Aichi 444-8787, Japan

${ }^{e}$ The Graduate University for Advanced Studies, Okazaki, Aichi 444-8787, Japan

${ }^{f}$ Faculty of Textile Science and Technology, Shinshu University, Ueda, Nagano 386-8567, Japan

\footnotetext{
*Corresponding author. Tel.: +81 268 215350; fax: +81 268215830 .

E-mail address: shochi@shinshu-u.ac.jp (S. Hochi).
} 


\section{Abstract}

The objective was to investigate the effects of developmental stage (fully-expanded or expanding blastocysts) and/or age (harvested on Days 7 or 8 ) on post-vitrification in vitro survival of bovine blastocysts derived from intracytoplasmic sperm injection (ICSI) or in vitro fertilization (IVF). Post-warming survival (re-expansion of blastocoele within $24 \mathrm{~h}$ ) of ICSIderived fully-expanded blastocysts $(80 \%)$ was similar to that of their IVF-derived counterparts (88\%). However, the ability of ICSI-derived expanding blastocysts to survive vitrification procedures $(61 \%)$ was lower than that of IVF-derived blastocysts $(85 \% ; \mathrm{P}<0.05)$, although the ICSI- and IVF-derived fresh blastocysts were of similar quality. The age of the blastocysts before vitrification did not affect cryotolerance for either ICSI-derived (73 and 59\% for Days 7 and 8 embryos, respectively) or IVF-derived blastocysts ( $86 \%$ for both Days 7 and 8 embryos). At $24 \mathrm{~h}$ of post-warming culture, ICSI-derived blastocysts surviving vitrification contained a higher proportion of dead cells than their IVF-derived counterparts (5 to $13 \%$ vs 2 to $4 \%$; $\mathrm{P}<$ 0.05), but these proportions were not different from those of fresh control embryos. There was an adverse effect of vitrification on the ability of blastocysts to hatch within $72 \mathrm{~h}$ of culture only in IVF-derived Day 8 blastocysts (41 and 70\% in vitrified and fresh control groups, respectively). In conclusion, the proportion of blastocysts that survived vitrification procedures was similar for ICSI- and IVF-derived bovine blastocysts if the former were cultured to the fully-expanded stage prior to vitrification, with no significant difference between embryos harvested on Day 7 versus Day 8.

Keywords: Bovine blastocysts; Cryotop; MVC vitrification; IVF; ICSI

\section{Introduction}

Sensitivity of bovine embryos to cryopreservation is affected by many factors, including the method of embryo production (in vivo- vs in vitro-derived), embryo quality, and developmental age and stage. Although numerous studies documented that the in vitro-produced embryos, mainly in vitro fertilization (IVF)-derived zygotes, have lower cryotolerance than their in vivoderived counterparts [1], the culture conditions used for IVF-derived presumptive zygotes greatly 
influenced cryotolerance of the resulting embryos [2,3]. Furthermore, faster-developing IVFderived bovine blastocysts (harvested $7 \mathrm{~d}$ after insemination) were tolerated cryopreservation better than slower-developing ones (harvested $8 \mathrm{~d}$ after insemination) [4-7]. Among blastocysts developed in the same day, embryos reaching more advanced stage or larger diameter were more likely to survive cryopreservation $[4,6,8,9]$.

The main cryoinjury during the freezing process resulted from formation of intracellular ice crystals [10]. Vitrification, which involves an extreme increase in the viscosity of the cryoprotective solution and completely eliminates ice crystal formation, has become a promising alternative to conventional freezing to improve cryotolerance of IVF-derived embryos $[2,11]$. The vitrification procedure requires utilization of extremely high concentrations of cryoprotectants and achieving extremely high rates of cooling and warming. The utilization of cryoprotactants in high concentrations may be toxic or result in osmotic stress to embryos [12]. However, the only way to induce vitrification using lower concentrations of cryoprotectants is to increase the cooling rate. Application of various cryodevices that reduced the volume of vitrification solution (minimum volume cooling: MVC) and/or decreasing the temperature of the liquid nitrogen (i.e., $\mathrm{N}_{2}$ slush) has been attempted to increase the rate of cooling [13]. Cryotop technology, an advanced version of the MVC procedure, was originally developed for cryopreservation of human oocytes and embryos [14], and subsequently successfully applied to vitrify oocytes from various species [15,16], IVF-derived embryos [17,18], and reconstructed embryos with somatic cell nuclei $[19,20]$.

Since the first successful production of live calves derived from intracytoplasmic sperm injection (ICSI) [21], there were subsequent attempts to improve the yield of ICSI-derived blastocysts $[22,23]$. We recently developed an improved activation regimen which increased bovine ICSI blastocyst yield up to $30 \%$, even with oocytes harvested from 1-d-stored ovaries [24]. To our best knowledge, there is only one publication regarding cryopreservation of ICSIderived bovine embryos [25]; in that study, $75 \%(12 / 16)$ of Day 7 expanded blastocysts and $88 \%$ (14/16) of Day 8 hatched blastocysts survived conventional two-step freezing. These cryosurvival rates in ICSI-derived embryos seemed comparable with those in IVF-derived counterparts. However, the ability of ICSI-derived bovine embryos to survive vitrification has apparently not been reported. 
The objective of the present study was to investigate the ability of ICSI- and IVF-derived bovine blastocysts to survive MVC (Cryotop) vitrification procedures, with special reference to the effect of developmental stage and age.

\section{Materials and methods}

\subsection{Experimental design}

A 2 X 2 X 2 factorial designed experiment was conducted. Bovine blastocysts produced either by IVF or ICSI were harvested 7 or $8 \mathrm{~d}$ after insemination. After being classified as either expanding or fully-expanded blastocysts, some of the embryos were subjected to differential cell staining to assess their quality, based on the total cell number and the inner cell mass (ICM) cell ratio. Most of the remaining blastocysts were vitrified-warmed by the MVC procedure, and cultured for $24 \mathrm{~h}$ to assess their revivability (re-expansion of the blastocoele). Then, blastocysts that survived vitrification were allocated to one of two further analyses; live/dead cell staining, or an additional $48 \mathrm{~h}$ culture to assess hatching ability. For both assessments, non-vitrified fresh blastocysts were used as controls.

\subsection{Chemicals and media}

Unless otherwise stated, all chemicals used in this study were purchased from SigmaAldrich Chemicals (St. Louis, MO, USA). Hepes-buffered TCM-199 (Earle's salt; Gibco BRL, Grand Island, NY, USA) containing $0.2 \mathrm{mM}$ sodium pyruvate and $50 \mu \mathrm{g} / \mathrm{mL}$ gentamycin sulfate (hereafter referred to as TCM-199) was supplemented with $10 \%$ fetal bovine serum (FBS; JRH Biosciences, Lenexa, KS, USA), 0.002 AU/mL FSH (Kawasaki-Mitaka Pharmaceutical, Kanagawa, Japan), and $1 \mu \mathrm{g} / \mathrm{mL}$ 17ß-estradiol for in vitro maturation (IVM), or with $3 \mathrm{mg} / \mathrm{mL}$ bovine serum albumin (BSA), with or without $1000 \mathrm{IU} / \mathrm{mL}$ hyaluronidase, for denuding or handling oocytes in atmosphere conditions, respectively. Modified Brackett and Oliphant (mBO) medium (IVF100; Institute for Functional Peptides, Yamagata, Japan) supplemented with $5 \mathrm{mM}$ theophylline was used as a sperm re-suspension medium after percoll-washing. The mBO medium, supplemented with $5 \mathrm{mg} / \mathrm{mL}$ BSA and $10 \mu \mathrm{g} / \mathrm{mL}$ heparin, was used for IVF. For short- 
term culture of oocytes before, during and after ICSI, TCM-199 supplemented with 5\% FBS was used. Modified synthetic oviduct fluid (mSOF) [26] supplemented with $30 \mu \mathrm{L} / \mathrm{mL}$ essential amino acids solution (X 50, Gibco-11130), $10 \mu \mathrm{L} / \mathrm{mL}$ non-essential amino acids solution (X 100, Gibco-11140), and 5\% FBS was used for culture of presumptive zygotes produced by IVF or ICSI. The base medium used for vitrification procedures (pre-equilibration, vitrification and post-warming dilution) was TCM-199 supplemented with 20\% FBS.

\subsection{Preparation of oocytes and spermatozoa}

Abattoir-derived bovine ovaries were transported to the laboratory in 10 to $12{ }^{\circ} \mathrm{C}$ saline within $24 \mathrm{~h}$ after slaughter. The contents of 2 to $8 \mathrm{~mm}$ follicles were aspirated with an $18-\mathrm{G}$ needle connected to a $10-\mathrm{mL}$ syringe. Oocytes surrounded with at least two layers of compact cumulus cells were matured in $100-\mu \mathrm{L}$ microdrop of the IVM medium for $22 \mathrm{~h}$ at $38.5^{\circ} \mathrm{C}$ under $5 \% \mathrm{CO}_{2}$ in air (10 to 12 oocytes per microdrop). Then, oocytes were freed from cumulus cells by brief vortex-mixing in TCM-199/BSA/hyaluronidase medium. Oocytes with an extruded first polar body were defined as matured, and either used directly for IVF or kept in TCM-199/FBS at $38.5^{\circ} \mathrm{C}$ under $5 \% \mathrm{CO}_{2}$ in air until use for ICSI (up to $3 \mathrm{~h}$ ).

Commercially available frozen semen from a Japanese Black bull (20 to 30 X $10^{6}$ sperm per $0.5-\mathrm{mL}$ straw) was thawed in water bath at $37^{\circ} \mathrm{C}$ for $30 \mathrm{~s}$ and the content was layered on the percoll density gradient consisting of $2 \mathrm{~mL}$ of $45 \%$ percoll above $2 \mathrm{~mL}$ of $90 \%$ percoll in a 15 $\mathrm{mL}$ conical tube. The tube was centrifuged for $20 \mathrm{~min}$ at $700 \mathrm{Xg}$, and the sperm pellet was resuspended in $\mathrm{mBO} /$ theophylline medium and washed twice for $5 \mathrm{~min}$ at $300 \mathrm{Xg}$ each.

\subsection{In vitro fertilization}

The sperm pellet after washing was re-suspended in the $\mathrm{mBO} / \mathrm{BSA} /$ heparin medium to yield a concentration of $25 \times 10^{6}$ cells $/ \mathrm{mL}$, and $20-\mu \mathrm{L}$ of the sperm suspension was added to $80-\mu \mathrm{L}$ microdrop of the $\mathrm{mBO} / \mathrm{BSA} / \mathrm{h}$ eparin medium containing 10 to 12 matured oocytes (final sperm concentration, $5 \times 10^{6}$ cells $/ \mathrm{mL}$ ). After $6 \mathrm{~h}$ of sperm/oocyte co-incubation at $38.5^{\circ} \mathrm{C}$ under $5 \%$ $\mathrm{CO}_{2}$ in air, $\leq 30$ presumptive zygotes were transferred to $250-\mu \mathrm{L}$ microdrop of the mSOF medium and cultured at $39.0{ }^{\circ} \mathrm{C}$ under $5 \% \mathrm{CO}_{2}, 5 \% \mathrm{O}_{2}$ and $90 \% \mathrm{~N}_{2}$. The day of IVF was defined 
as Day 0, and the cleavage rate and the developmental rate into blastocysts were determined on Day 2 and on Days 7 or 8 , respectively.

\subsection{Intracytoplasmic sperm injection}

A sperm suspension $\left(25 \times 10^{6}\right.$ cells $\left./ \mathrm{mL}\right)$ was treated with $5 \mathrm{mM}$ dithiothreitol (DTT) in the $\mathrm{mBO}$ medium for $20 \mathrm{~min}$ at $37^{\circ} \mathrm{C}$, followed by washing twice with the mBO medium $(5 \mathrm{~min}$, $300 \mathrm{X} g$ each). Then, ICSI was performed using a piezo-driven micromanipulator (PMASCT150; PrimeTech, Ibaraki, Japan), as described previously [24]. The ICSI oocytes were first activated with $5 \mathrm{mM}$ ionomycin in $\mathrm{Ca}^{2+} / \mathrm{Mg}^{2+}$-free phosphate buffered saline (PBS) for $5 \mathrm{~min}$, and after $4 \mathrm{~h}$ culture in $100-\mu \mathrm{L}$ microdrops of the TCM-199/FBS medium at $38.5^{\circ} \mathrm{C}$ under $5 \%$ $\mathrm{CO}_{2}$ in air, a second activation was done with $7 \%$ ethanol in TCM-199 supplemented with $1 \%$ polyvinylpyrollidone (PVP; $40 \mathrm{kDa}$ ) for $5 \mathrm{~min}$. Presumptive zygotes were cultured for up to $8 \mathrm{~d}$, as described above for IVF-derived zygotes.

\subsection{Assessment of fresh blastocysts}

Blastocysts harvested on Day 7 or 8 were classified into one of two developmental stages; fully-expanded blastocysts that were $\geq 200 \mu \mathrm{m}$ in diameter, or expanding blastocysts that were 140 to $199 \mu \mathrm{m}$ in diameter. Some of the blastocysts were differentially stained with Hoechst 33342 and propidium iodide (PI) for assessment of ICM cells and trophectoderm (TE) cells, as reported [27]. Under an epifluorescence microscope, ICM cell nuclei labeled with Hoechst 33342 appeared blue, whereas TE cell nuclei labeled with PI and Hoechst 33342 appeared pink. Thus, blastocysts' total cell number (TE + ICM) and the ICM ratio (ICM / \{TE + ICM $\}$ X 100) were determined.

\subsection{Vitrification and warming}

Blastocysts were subjected to MVC vitrification according to the method described previously [28], with minor modifications. One to five blastocysts were equilibrated with $7.5 \%$ ethylene glycol (EG; Wako Pure Chemical Industries Co., Osaka, Japan) and 7.5\% 
dimethylsulfoxide (DMSO; Wako) in TCM-199/20\% FBS base medium for 3 min at room temperature, and then transferred into a vitrification solution consisting of $15 \% \mathrm{EG}, 15 \% \mathrm{DMSO}$, and $0.5 \mathrm{M}$ sucrose in the base medium for approximately $40 \mathrm{~s}$ at room temperature. Within this $40 \mathrm{~s}$, blastocysts were loaded onto the top of the polypropylene strip of a Cryotop (Kitazato BioPharma Co., Shizuoka, Japan) with a minimal amount of vitrification solution, and then quickly immersed into liquid nitrogen $\left(\mathrm{LN}_{2}\right)$.

After storage for $>1 \mathrm{~d}$ in $\mathrm{LN}_{2}$ tank, blastocysts were warmed by immersing the polypropylene strip of a Cryotop into $3 \mathrm{~mL}$ of the base medium containing $1 \mathrm{M}$ sucrose at $38{ }^{\circ} \mathrm{C}$, and kept for $1 \mathrm{~min}$. The blastocysts were transferred to base medium at room temperature in a stepwise manner $(0.5,0.25$, and $0 \mathrm{M}$ sucrose for 3,5 , and $5 \mathrm{~min}$, respectively). Finally, blastocysts were cultured in mSOF medium at $39.0{ }^{\circ} \mathrm{C}$ under $5 \% \mathrm{CO}_{2}, 5 \% \mathrm{O}_{2}$ and $90 \% \mathrm{~N}_{2}$.

\subsection{Post-warming assays}

Vitrified-warmed blastocysts were cultured in $250-\mu \mathrm{L}$ microdrops of the mSOF medium for $24 \mathrm{~h}$ at $39.0{ }^{\circ} \mathrm{C}$ under $5 \% \mathrm{CO}_{2}, 5 \% \mathrm{O}_{2}$ and $90 \% \mathrm{~N}_{2}$, and their cryosurvival was assessed by reexpansion of the blastocoele. Thereafter, surviving embryos, as well as the corresponding fresh control Days 8 or 9 embryos, were randomly allocated either to additional $48 \mathrm{~h}$ culture for determination of their ability to hatch, or to live/dead cell staining according to the method described previously [2], with minor modifications. Regarding assessment of hatching ability, embryos with more than half of embryonic part escaped out the zona were defined as hatched. For live/dead cell staining, blastocysts were incubated at $38.5^{\circ} \mathrm{C}$ in PBS supplemented with 3 $\mathrm{mg} / \mathrm{mL}$ BSA and $20 \mu \mathrm{g} / \mathrm{mL}$ PI for $15 \mathrm{~min}$, fixed in cold ethanol for $5 \mathrm{~min}$, and then stained with $25 \mu \mathrm{g} / \mathrm{mL}$ Hoechst 33342 for $5 \mathrm{~min}$ at room temperature. Thereafter, they were washed once with glycerol/1,4-diazabicyclo[2.2.2] octane and mounted on a glass slide with the same medium. Under an epifluorescence microscope, live cells labeled with Hoechst 33342 appeared blue and dead cells labeled with PI and Hoechst 33342 appeared pink. Thus, total cell number of the blastocysts (live + dead cells) and the dead cell ratio (dead / total cells X 100) were determined.

\subsection{Statistical analysis}


Proportions of embryos surviving the MVC vitrification and hatching were compared by Fisher's exact probability test. Proportional data regarding quality analysis of the embryos (ICM ratio and dead cell ratio) were arcsin-transformed and subjected to one-way ANOVA. Differences among groups were identified with Bonferroni's post-hoc multiple comparison test. Mean total cell number of the blastocysts was compared by one-way ANOVA. For all analyses, $\mathrm{P}<0.05$ was considered statistically significant.

\section{Results}

\subsection{Quality of IVF- and ICSI-derived fresh blastocysts}

Out of 1,384 IVF-derived zygotes cultured, 1,101 (80\%) cleaved on Day 2, and $406(29 \%)$ and $156(11 \%)$ developed to expanding or fully-expanded blastocysts on Days 7 and 8 , respectively. In addition, out of 1,061 ICSI-derived zygotes cultured, 798 (68\%) cleaved on Day 2, and $155(15 \%)$ and $87(8 \%)$ developed to expanding or fully-expanded blastocysts on Days 7 and 8 . Based on quality analysis of the fresh blastocysts (differential cell staining), the ICM cell ratio (31 to 35\%) was not affected by the method of embryo production (IVF vs ICSI), the day of blastocyst harvest (Day 7 vs Day 8), or developmental stage (expanding vs fully-expanded), as shown (Table 1). Fully-expanded blastocysts tended to have higher total cell number (ranged from 125 to 136) than expanding blastocysts (ranged from 96 to 108), regardless of the method of embryo production or day of blastocyst harvest.

\subsection{Assessments of IVF- and ICSI-derived blastocysts after MVC vitrification}

The post-warming survival rates of IVF-derived blastocysts ( 84 to $89 \%$ ) were not affected by developmental stage or age (Table 2). Conversely in the ICSI group, the ability of fullyexpanded Day 7 or 8 blastocysts to survive vitrification procedures tended to be higher than that of expanding-stage counterparts; the difference reached significance when the data were pooled across the day of blastocyst harvest ( 80 vs $61 \%$; $<0.05$ ). Cryosurvival of the IVF-derived expanding blastocysts were significantly higher than that of the ICSI-derived counterparts, regardless of the day of blastocyst harvest. Due to these differences, the overall cryosurvival of 
ICSI-derived blastocysts was significantly lower than that of IVF-derived counterparts (69 vs $86 \%)$.

The ICSI-derived blastocysts surviving the MVC vitrification procedures contained a higher proportion of dead cells than IVF-derived counterparts ( 5 to $13 \%$ vs 2 to $4 \%$; $\mathrm{P}<0.05$ ), but these proportions were not different from those of fresh control embryos (ICSI; 5 to $15 \%$, IVF; 6 to $8 \%$; Table 3). Total cell numbers in the vitrified-warmed blastocysts were comparable to those in the fresh control embryos, except in IVF-derived, Day 7 fully-expanded blastocysts.

The remaining blastocysts that survived the MVC vitrification were further cultured for up to $72 \mathrm{~h}$ to assess their ability to hatch from zonae pellucidae in vitro. An adverse effect of MVC vitrification on the ability of blastocysts to hatch was found only in IVF-derived, Day 8 blastocysts (hatching rates of 41 and $70 \%$ in vitrified and fresh control groups, respectively; Table 4). The hatching rate of Day 8 vitrified-warmed blastocysts (41\%) was also lower than that of Day 7 counterparts (63\%). Hatching rate of ICSI-derived, Day 7 expanding blastocysts after vitrification (33\%) was lower than that of ICSI-derived, Day 7 fully-expanded blastocysts $(73 \%)$, as well as that of IVF-derived, Day 7 expanding blastocysts $(65 \%)$.

\section{Discussion}

Information regarding cryotolerance of the ICSI-derived bovine embryos is limited to a report by Keskintepe and Brackett [25]; in that study, 16 expanded blastocysts harvested on Day 7 , plus 16 blastocysts that hatched after an additional $18 \mathrm{~h}$ of culture were exposed to a conventional freezing regimen, resulting in cryosurvival rates of 75 and $88 \%$, respectively. In the present study, ICSI-derived, fully-expanded bovine blastocysts harvested on Days 7 or 8 had similar ability to survive the MVC vitrification with IVF-derived counterparts. Conversely, expanding blastocysts derived from ICSI, but not IVF, were more sensitive to MVC vitrification than fully-expanded blastocysts. Based on differential cell staining of fresh blastocysts, we inferred that ICSI-derived expanding blastocysts and their IVF-derived counterparts were of comparable quality (in total cell number and the ICM ratio); therefore, differences in embryo quality before vitrification apparently did not account for the higher sensitivity of ICSI-derived expanding blastocysts to MVC vitrification. The relationship between the size of blastocysts and their cryotolerance has been investigated; larger blastocysts tolerated cryopreservation better 
than the smaller ones $[9,25,29,30]$, with the exception of one report in cattle [3]. For speciesspecific reasons, there was opposite size-dependent cryotolerance in human [31] and horse [32] blastocysts. It has been reported that tolerance to vitrification of in vitro-produced bovine blastocysts was improved when they were larger than 150 to $160 \mu \mathrm{m}$ in diameter $[6,9,29]$. Perhaps differential cryotolerance between IVF- and ICSI-derived expanding blastocysts was due to ICSI-derived expanding blastocysts being comparatively smaller than their IVF-derived counterparts, even though the mean total cell number was comparable. Further research is needed to determine why size-dependent cryotolerance was more prominent in ICSI-derived versus IVF-derived blastocysts.

There is also a general agreement that faster-developing bovine embryos are more likely to survive cryopreservation [4-7]. Therefore, in most studies of embryo cryopreservation, either all blastocysts harvested on Day 7 were used, or a subset was chosen, based on morphological characteristics. In the present study, the cryosurvival rate of Day 7 IVF-derived blastocysts achieved using the Cryotop (86\%) was slightly lower than 94\% survival reported using the same cryodevice [17], and was comparable to or even higher than those achieved using other cryodevices for MVC vitrification, e.g., open-pulled straws (OPS; 89 to 97\%) [33], hand-pulled glass micropipettes (84 to 94\%) [34], and electron microscope grids (58 to 98\%) [8]. Moreover, in the present study, Day 8 blastocysts had similar survivability to their Day 7 counterparts (derived from either IVF or ICSI). We have previously reported similar results in domestic cat blastocysts produced in vitro [28]. Dinnyés et al. [29] reported a reasonable cryosurvival rate from IVF-derived Day 8 bovine embryos at the fully-expanded and hatched blastocyst stages $(<90 \%)$; however, those embryos were produced by prolonged culture of Day 7 blastocysts.

A possible adverse effect of the cryopreservation process is to reduce the ability of the postwarming embryos to continue mitotic division [35], or to induce apoptosis or necrosis in some embryonic cells, especially ICM cells [36]. In the present study, except for IVF-derived Day-7 fully-expanded blastocysts, there was no adverse effect of vitrification/warming process on the total cell number of the blastocysts, which was in agreement with previous results reported for the mouse [37], cow [38], and cat [28]. The proportions of dead cells in vitrified/warmed blastocysts ( 2 to $13 \%$ ) were comparable to those in fresh control blastocysts (5 to $15 \%$ ), which was contradictory to previous studies with higher proportion of dead cells in vitrified/warmed embryos compared to fresh ones (14 vs 1 to $2 \%$ [2] and 20 to 45 vs 5 to $14 \%$ [3]). Perhaps these 
differences were due to better suitability of the Cryotop technology compared to the OPS or straw vitrification procedures applied in the previous studies. Based on a higher proportion of dead cells in the ICSI-derived fully-expanded blastocysts after vitrification compared to the IVFderived counterparts, perhaps embryonic cells in ICSI-derived blastocysts were more sensitive to vitrification procedures than their IVF-derived counterparts. However, non-vitrified control ICSI-derived blastocysts and vitrified-warmed blastocysts contained similar proportions of dead cells.

Although the ability of blastocysts to hatch out of their zonae can be used to assess embryo quality, hatching was greatly influenced by culture conditions [39]. In the present study, ICSIderived expanding blastocysts hatched less than their IVF-derived counterparts, although the initial total cell number and the proportions of the ICM were not significantly different. Perhaps either the culture conditions used in the present study were not optimal to support the development of the ICSI-derived embryos after blastulation, or the quality of the ICSI-derived blastocysts was inferior to those of their IVF-derived counterparts. The absence of a clear relationship between developmental age and hatching ability in the ICSI-derived blastocysts may be due to the limited number of embryos subjected to additional culture. Earlier initiation of hatching in ICSI-derived blastocysts, due to the presence of a piezo-drilled small opening in the zona pellucida, may have contributed to their lower hatching ability. The manner of the hatching process frequently observed in the ICSI-derived blastocysts (data not shown) was similar to that previously reported in nuclear-transferred bovine zygotes [19].

In conclusion, the present study is apparently the first to document that ICSI-derived fullyexpanded ( $\geq 200 \mu \mathrm{m}$ in diameter) bovine blastocysts and IVF-derived blastocysts had similar ability to survive MVC-Cryotop vitrification. Since ICSI-derived, but not IVF-derived, expanding blastocysts were slightly sensitive to vitrification, it is recommended to prolong in vitro culture of ICSI-derived embryos (until they are fully expanded) prior to cryopreservation. 


\section{Acknowledgments}

This work was supported in part by a Grant-in-Aid for Scientific Research from the Japan Society for the Promotion of Sciences (No. 20580305). This paper is dedicated to the first principal, Chotaro Harizuka, on the occasion of $100^{\text {th }}$ anniversary of the Faculty of Textile Science and Technology, Shinshu University. 


\section{References}

[1] Massip A, Mermillod P, Dinnyes A. Morphology and biochemistry of in-vitro produced bovine embryos: implications for their cryopreservation. Hum Reprod 1995;10:3004-11.

[2] Mucci N, Aller J, Kaiser GG, Hozbor F, Cabodevila J, Alberio RH. Effect of estrous cow serum during bovine embryo culture on blastocyst development and cryotolerance after slow freezing or vitrification. Theriogenology 2006;65:1551-62.

[3] Shirazi A, Nazari H, Ahmadi E, Heidari B, Shams-Esfandabadi N. Effect of culture system on survival rate of vitrified bovine embryos produced in vitro. Cryobiology 2009;58:28590.

[4] Han YM, Yamashina H, Koyama N, Lee KK, Fukui Y. Effects of the quality and the developmental stage on the survival of IVF-Derived bovine blastocysts cultured in vitro after freezing and thawing. Theriogenology 1994;42:645-54.

[5] Saha S, Rajamahendran R, Boediono A, Sumantri C, Suzuki T. Viability of bovine blastocysts obtained after 7,8 or 9 days of culture in vitro following vitrification and onestep rehydration. Theriogenology 1996;46:331-43.

[6] Dinnyés A, Lonergan P, Fair T, Boland MP, Yang X. Timing of the first cleavage postinsemination affects cryosurvival of in vitro-produced bovine blastocysts. Mol Reprod Dev 1999;53:318-24.

[7] Gómez E, Rodríguez A, Muñoz M, Caamaño JN, Hidalgo CO, Morán E, et al. Serum free embryo culture medium improves in vitro survival of bovine blastocysts to vitrification. Theriogenology 2008;69:1013-21.

[8] Park SP, Kim EY, Kim DI, Park NH, Won YS, Yoon SH, et al. Simple, efficient and successful vitrification of bovine blastocysts using electron microscope grids. Hum Reprod 1999;14:2838-43.

[9] George F, Daniaux C, Genicot G, Verhaeghe B, Lambert P, Donnay I. Set up of a serumfree culture system for bovine embryos: embryo development and quality before and after transient transfer. Theriogenology 2008;69:612-23.

[10] Leibo SP. Fundamental cryobiology of mouse ova and embryos. In: Ciba Foundation Symposium 52, The Freezing of Mammalian Embryos. Elsevier; 1977. p. 69-96. 
[11] Nedambale TL, Dinnyés A, Groen W, Dobrinsky JR, Tian XC, Yang X. Comparison on in vitro fertilized bovine embryos cultured in KSOM or SOF and cryopreserved by slow freezing or vitrification. Theriogenology 2004;62:437-49.

[12] Liebermann J, Nawroth F, Isachenko V, Isachenko E, Rahimi G, Tucker MJ. Potential importance of vitrification in reproductive medicine. Biol Reprod 2002;67:1671-80.

[13] Vajta G, Kuwayama M. Improving cryopreservation systems. Theriogenology 2006;65:236-44.

[14] Kuwayama M, Kato O. All-round vitrification method for human oocytes and embryos. J Assist Reprod Genet 2000;17:477.

[15] Liu Y, Du Y, Lin L, Li J, Kragh PM, Kuwayama M, et al. Comparison of the efficiency of open pulled straw (OPS) and Cryotop vitrification for cryopreservation of in vitro matured pig oocytes. Cryo Letters 2008;29:315-20.

[16] Morató R, Izquierdo D, Paramio MT, Mogas T. Cryotops versus open-pulled straws (OPS) as carriers for the cryopreservation of bovine oocytes: effects on spindle and chromosome configuration and embryo development. Cryobiology 2008;57:137-41.

[17] Kelly JM, Kleemann DO, Kuwayama M, Walker SK. Vitrification of in vitro-produced bovine and ovine embryos using the minimum volume cooling cryotop method. Reprod Fertil Dev 2004;16:172-3.

[18] De Rosa A, Attanasio L, Boccia L, Pellerano G, Campanile G, Gasparrini B. Cryotop vitrification for in vitro-produced buffalo (Bubalus bubalis) embryos. Reprod Fertil Dev 2007; 19:174-5.

[19] Laowtammathron C, Lorthongpanich C, Ketudat-Cairns M, Hochi S, Parnpai R. Factors affecting cryosurvival of nuclear-transferred bovine and swamp buffalo blastocysts: effects of hatching stage, linoleic acid-albumin in IVC medium and Ficoll supplementation to vitrification solution. Theriogenology 2005;64:1185-96.

[20] Du Y, Zhang Y, Li J, Kragh PM, Kuwayama M, Ieda S, et al. Simplified cryopreservation of porcine cloned blastocysts. Cryobiology 2007;54:181-7.

[21] Goto K, Kinoshita A, Takuma Y, Ogawa K. Fertilization of bovine oocytes by the injection of immobilised, killed spermatozoa. Vet Rec 1990;127:517-20. 
[22] Horiuchi T, Emuta C, Yamauchi Y, Oikawa T, Numabe T, Yanagimachi R. Birth of normal calves after intracytoplasmic sperm injection of bovine oocytes: a methodological approach. Theriogenology 2002;57:1013-24.

[23] Galli C, Vassiliev I, Lagutina I, Galli A, Lazzari G. Bovine embryo development following ICSI: effect of activation, sperm capacitation and pre-treatment with dithiothreitol. Theriogenology 2003;60:1467-80.

[24] Abdalla H, Shimoda M, Hirabayashi M, Hochi S. A combined treatment of ionomycin with ethanol improves blastocyst development of bovine oocytes harvested from stored ovaries and microinjected with spermatozoa. Theriogenology 2009;72:453-60.

[25] Keskintepe L, Brackett BG. Cryopreservation of bovine blastocysts obtained by intracytoplasmic sperm injection. Theriogenology 2000;53:1041-52.

[26] Holm P, Booth PJ, Schmidt MH, Greve T, Callesen H. High bovine blastocyst development in a static in vitro production system using SOFaa medium supplemented with sodium citrate and myo-inositol with or without serum-proteins. Theriogenology 1999;52:683-700.

[27] Thouas GA, Korfiatis NA, French AJ, Jones GM, Trounson AO. Simplified technique for differential staining of inner cell mass and trophectoderm cells of mouse and bovine blastocysts. Reprod Biomed Online 2001;3:25-9.

[28] Tsujioka T, Otzdorff C, Braun J, Hochi S. Effect of post-IVF developmental kinetics on in vitro survival of vitrified-warmed domestic cat blastocysts. Reprod Domest Anim 2008;43:323-7.

[29] Dinnyés A, Carolan C, Lonergan P, Massip A, Mermillod P. Survival of frozen or vitrified bovine blastocysts produced in vitro in synthetic oviduct fluid. Theriogenology 1996;46:1425-39.

[30] Berthelot F, Venturi E, Cognié J, Furstoss V, Martinat-Botté F. Development of OPS vitrified pig blastocysts: effects of size of the collected blastocysts, cryoprotectant concentration used for vitrification and number of blastocysts transferred. Theriogenology 2007;68:178-85.

[31] Vanderwalmen P, Bertin G, Debauche CH, Standaert V, van Roosendaal E, Vandervost M, et al. Birth after vitrification at morula and blastocyst stage: effect of artificial reduction of the blastocoelic cavity before vitrification. Hum Reprod 2002;17:744-51. 
[32] Hochi S, Fujimoto T, Oguri N. Large equine blastocysts are damaged by vitrification procedures. Reprod Fertil Dev1995;7:113-7.

[33] Vajta G, Rindom N, Peura TT, Holm P, Greve T, Callesen H. The effect of media, serum and temperature on in vitro survival of bovine blastocysts after Open Pulled Straw (OPS) vitrification. Theriogenology 1999;52:939-48.

[34] Vieira AD, Forell F, Feltrin C, Rodrigues JL. In-straw cryoprotectant dilution of IVP bovine blastocysts vitrified in hand-pulled glass micropipettes. Anim Reprod Sci 2007;99:377-83.

[35] Kaidi S, Van Langendonckt A, Massip A, Dessy F, Donnay I. Cellular alteration after dilution of cryoprotective solutions used for the vitrification of in vitro-produced bovine embryos. Theriogenology 1999;52:515-25.

[36] Gómez E, Muñoz M, Rodríguez A, Caamaño JN, Facal N, Díez C. Vitrification of bovine blastocysts produced in vitro inflicts selective damage to the inner cell mass. Reprod Domest Anim 2009;44:194-9.

[37] Sheehan CB, Lane M, Gardner DK. The CryoLoop facilitates re-vitrification of embryos at four successive stages of development without impairing embryo growth. Hum Reprod 2006;21:2978-84.

[38] George F, Vrancken M, Verhaeghe B, Verhoeye F, Schneider YJ, Massip A, et al. Freezing of in vitro produced bovine embryos in animal protein-free medium containing vegetal peptones. Theriogenology 2006;66:1381-90.

[39] Krisher RL, Lane M, Bavister BD. Developmental competence and metabolism of bovine embryos cultured in semi-defined and defined culture media. Biol Reprod 1999;60:134552. 
Table 1. Mean \pm SEM number of total cells and percentage of inner cell mass ( $\%$ ICM) in IVFand ICSI-derived bovine blastocysts, based on differential staining.

\begin{tabular}{|c|c|c|c|c|c|c|c|}
\hline \multirow[b]{2}{*}{ Origin } & \multirow{2}{*}{$\begin{array}{l}\text { Developmental } \\
\text { stage }\end{array}$} & \multicolumn{3}{|c|}{ Day 7 blastocysts } & \multicolumn{3}{|c|}{ Day 8 blastocysts } \\
\hline & & No. & Total & $\%$ ICM & No. & Total & $\%$ ICM \\
\hline \multirow[t]{2}{*}{ IVF } & Fully-expanded & 16 & $135 \pm 6$ & $34 \pm 2$ & 11 & $125 \pm 9$ & $32 \pm 3$ \\
\hline & Expanding & 17 & $109 \pm 5$ & $35 \pm 2$ & 10 & $104 \pm 8$ & $31 \pm 2$ \\
\hline \multirow[t]{2}{*}{ ICSI } & Fully-expanded & 10 & $136 \pm 6$ & $30 \pm 1$ & 5 & $134 \pm 9$ & $35 \pm 2$ \\
\hline & Expanding & 13 & $106 \pm 6$ & $33 \pm 2$ & 10 & $96 \pm 6$ & $31 \pm 3$ \\
\hline
\end{tabular}


Table 2. Effect of developmental stage and age on in vitro survival of IVF- and ICSIderived bovine blastocysts after MVC vitrification.

\begin{tabular}{lllll}
\hline \multirow{2}{*}{ Origin } & Developmental & \multicolumn{2}{c}{ Harvest } & \\
\cline { 3 - 4 } & stage & Day 7 & Day 8 & Subtotal \\
\hline \multirow{2}{*}{ IVF } & Fully-expanded & $58 / 66(88)$ & $25 / 28(89)$ & $83 / 94(88)$ \\
& Expanding & $63 / 74(85)^{\mathrm{x}}$ & $32 / 38(84)^{\mathrm{x}}$ & $95 / 112(85)^{\mathrm{x}}$ \\
& Subtotal & $121 / 140(86)^{\mathrm{x}}$ & $57 / 66(86)^{\mathrm{x}}$ & $178 / 206(86)^{\mathrm{x}}$ \\
\multirow{2}{*}{ ICSI } & Fully-expanded & $25 / 30(83)$ & $11 / 15(73)$ & $36 / 45(80)^{\mathrm{a}}$ \\
& Expanding & $30 / 45(67)^{\mathrm{y}}$ & $8 / 17(47)^{\mathrm{y}}$ & $38 / 62(61)^{\mathrm{by}}$ \\
& Subtotal & $55 / 75(73)^{\mathrm{y}}$ & $19 / 32(59)^{\mathrm{y}}$ & $74 / 107(69)^{\mathrm{y}}$ \\
\hline
\end{tabular}

No. re-expanded embryos / No. vitrified-warmed embryos (\%)

${ }^{\mathrm{a}, \mathrm{b}}$ Difference $(\mathrm{P}<0.05)$ between the two developmental stages within the IVF or ICSI groups

${ }^{\mathrm{x}, \mathrm{y}}$ Difference $(\mathrm{P}<0.05)$ between IVF and ICSI groups 
Table 3. Mean \pm SEM number of total cells and proportion of dead cells in IVF- or ICSI-derived bovine blastocysts that survived MVC vitrification (assessed after $24 \mathrm{~h}$ of post-warming culture).

\begin{tabular}{|c|c|c|c|c|c|c|c|c|}
\hline \multirow[b]{2}{*}{ Origin } & \multirow{2}{*}{$\begin{array}{l}\text { Day of } \\
\text { harvest }\end{array}$} & \multirow{2}{*}{$\begin{array}{l}\text { Developmental } \\
\text { stage }\end{array}$} & \multicolumn{3}{|c|}{ Vitrified blastocysts } & \multicolumn{3}{|c|}{ Fresh blastocysts } \\
\hline & & & No. & Total & $\%$ Dead & No. & Total & $\%$ Dead \\
\hline \multirow[t]{4}{*}{ IVF } & 7 & Fully-expanded & 16 & $130 \pm 9^{f}$ & $3 \pm 1^{\mathrm{y}}$ & 15 & $179 \pm 12^{\text {acex }}$ & $6 \pm 2$ \\
\hline & & Expanding & 15 & $116 \pm 8$ & $4 \pm 2$ & 16 & $104 \pm 7^{b}$ & $7 \pm 2$ \\
\hline & 8 & Fully-expanded & 14 & $113 \pm 10$ & $2 \pm 1^{y}$ & 12 & $118 \pm 15^{\mathrm{d}}$ & $8 \pm 4$ \\
\hline & & Expanding & 16 & $95 \pm 11$ & $3 \pm 1$ & 10 & $95 \pm 9$ & $6 \pm 2$ \\
\hline \multirow[t]{4}{*}{ ICSI } & 7 & Fully-expanded & 14 & $140 \pm 12^{\mathrm{a}}$ & $9 \pm 3^{x}$ & 13 & $146 \pm 14^{y}$ & $15 \pm 4$ \\
\hline & & Expanding & 15 & $102 \pm 7^{\mathrm{b}}$ & $5 \pm 1$ & 11 & $126 \pm 15^{\mathrm{c}}$ & $8 \pm 2$ \\
\hline & 8 & Fully-expanded & 7 & $102 \pm 13$ & $13 \pm 4^{x}$ & 4 & $114 \pm 16$ & $5 \pm 2$ \\
\hline & & Expanding & 6 & $94 \pm 11$ & $7 \pm 2$ & 9 & $86 \pm 5^{\mathrm{d}}$ & $7 \pm 6$ \\
\hline
\end{tabular}

${ }^{a, b}$ Difference $(\mathrm{P}<0.05)$ between the two developmental stages within the IVF or ICSI groups ${ }^{c, d}$ Difference $(\mathrm{P}<0.05)$ between the $2 \mathrm{~d}$ of blastocyst harvest within the IVF or ICSI groups ${ }^{e, f}$ Difference $(\mathrm{P}<0.05)$ between vitrified and fresh blastocysts within the IVF or ICSI groups ${ }^{\mathrm{x}, \mathrm{y}}$ Difference $(\mathrm{P}<0.05)$ between the IVF and ICSI groups 
Table 4. Hatching ability of IVF- or ICSI-derived bovine blastocysts that survived MVC vitrification (assessed after $72 \mathrm{~h}$ of post-warming culture).

\begin{tabular}{|c|c|c|c|c|c|}
\hline \multirow[b]{2}{*}{ Origin } & \multirow{2}{*}{$\begin{array}{l}\text { Developmental } \\
\text { stage }\end{array}$} & \multicolumn{2}{|c|}{ Day 7 blastocysts } & \multicolumn{2}{|c|}{ Day 8 blastocysts } \\
\hline & & Vitrified & Fresh control & Vitrified & Fresh control \\
\hline \multirow[t]{3}{*}{ IVF } & Fully-expanded & $26 / 42(62)$ & $27 / 36(75)$ & $6 / 11(55)$ & 15 / $19(78)$ \\
\hline & Expanding & $31 / 48(65)^{\mathrm{cx}}$ & 22 / $40(55)$ & $5 / 16(31)^{d}$ & $13 / 21(62)$ \\
\hline & Subtotal & $57 / 90(63)^{\mathrm{c}}$ & 49 / 76 (64) & $11 / 27(41)^{\mathrm{df}}$ & $28 / 40(70)^{\mathrm{e}}$ \\
\hline \multirow[t]{3}{*}{ ICSI } & Fully-expanded & $8 / 11(73)^{\mathrm{a}}$ & $5 / 9(56)$ & $2 / 4(50)$ & $5 / 9(56)$ \\
\hline & Expanding & $5 / 15(33)^{\text {by }}$ & $4 / 10(40)$ & $0 / 2(0)$ & 5 / $13(38)$ \\
\hline & Subtotal & $13 / 26(50)$ & 9 / 19 (47) & 2 / $6(33)$ & $10 / 22(45)$ \\
\hline
\end{tabular}

No. hatched embryos / No. surviving, cultured embryos (\%)

${ }^{\mathrm{a}, \mathrm{b}}$ Difference $(\mathrm{P}<0.05)$ between the two developmental stages within the IVF or ICSI groups

${ }^{\mathrm{c}, \mathrm{d}}$ Difference $(\mathrm{P}<0.05)$ between the $2 \mathrm{~d}$ of blastocyst harvest within the IVF or ICSI groups

${ }^{\mathrm{e}, \mathrm{f}}$ Difference $(\mathrm{P}<0.05)$ between vitrified and fresh blastocysts within the IVF or ICSI groups

${ }^{\mathrm{x}, \mathrm{y}}$ Difference $(\mathrm{P}<0.05)$ between the IVF and ICSI groups 